\title{
Modifying Cement Hydration with NS@PCE Core-Shell Nanoparticles
}

\author{
Yue Gu, ${ }^{1,2}$ Qianping Ran, ${ }^{2,3}$ Wei She, ${ }^{1}$ and Jiaping Liu ${ }^{1,2,3}$ \\ ${ }^{1}$ School of Materials Science and Engineering, Southeast University, Nanjing 211189, China \\ ${ }^{2}$ State Key Laboratory of High Performance Civil Engineering Materials, Nanjing 210008, China \\ ${ }^{3}$ Jiangsu Research Institute of Building Science, Nanjing, Jiangsu 210008, China \\ Correspondence should be addressed to Yue Gu; gubetter@163.com and Wei She; weishe@seu.edu.cn
}

Received 31 March 2017; Accepted 30 May 2017; Published 27 July 2017

Academic Editor: Kedsarin Pimraksa

Copyright (C) 2017 Yue Gu et al. This is an open access article distributed under the Creative Commons Attribution License, which permits unrestricted use, distribution, and reproduction in any medium, provided the original work is properly cited.

\begin{abstract}
It is generally accepted that fine particles could accelerate cement hydration process, or, more specifically, this accelerating effect can be attributed to additional surface area introduced by fine particles. In addition to this view, the surface state of fine particles is also an important factor, especially for nanoparticles. In the previous study, a series of nano- $\mathrm{SiO}_{2}$-polycarboxylate superplasticizer core-shell nanoparticles (NS@PCE) were synthesized, which have a similar particle size distribution but different surface properties. In this study, the impact of NS@PCE on cement hydration was investigated by heat flow calorimetry, mechanical property measurement, XRD, and SEM. Results show that, among a series of NS@PCE, NS@PCE-2 with a moderate shell-core ratio appeared to be more effective in accelerating cement hydration. As dosage increases, the efficiency of NS@PCE-2 would reach a plateau which is quantified by various characteristic values. Compressive strength results indicate that strength has a linear correlation with cumulative heat release. A hypothesis was proposed to explain the modification effect of NS@PCE, which highlights a balance between initial dispersion and pozzolanic reactivity. This paper provides a new understanding for the surface modification of supplementary cementitious materials and their application and also sheds a new light on nano- $\mathrm{SiO}_{2}$ for optimizing cement-based materials.
\end{abstract}

\section{Introduction}

Concrete is still the most widely used construction material in our planet which contributed $8 \sim 10 \%$ of the worldwide anthropogenic $\mathrm{CO}_{2}$ emission $[1,2]$. To reduce the environmental footprint triggered by concrete, one effective strategy is to utilize supplementary cementitious materials (SCMs) to replace a portion of cement, the main binder component of concrete. This is particularly significant in a $\mathrm{CO}_{2}$-penalized economy, where the reduced $\mathrm{CO}_{2}$ impact of cement could bring about economic, social, and environmental benefits. SCMs commonly refer to fly ash, ground granulated blasted furnace slag, limestone, and calcined clays. Unfortunately, the addition of SCMs with a high volume would often adversely impact the development of mechanical property, especially at the early age. To overcome the undesired negative consequence, more recently, nanomaterials have been explored as superior filler agents to improve the early age property [3-5]. For instance, Yehdego and Peethamparan [4] revealed that nanomaterials modified high volume fly ash concrete could obtain doubled compressive strength in comparison to pristine unmodified sample at $24 \mathrm{~h}$.

Nanotechnology is in the forefront of materials research, as it changed the traditional vision about the synthesis, modification, and control of materials. To respond to constant curiosity around nanotechnology in cement and concrete research area, various nanoparticles, such as nano$\mathrm{SiO}_{2}$ [6], nano- $\mathrm{Al}_{2} \mathrm{O}_{3}[7]$, nano- $\mathrm{TiO}_{2}[8,9]$, nanoclay [10], and graphene [11], have been added to enhance the early age properties of cementitious materials. Among all the nanoparticles, the incorporation of nano- $\mathrm{SiO}_{2}$ (NS) into cementitious materials has been most extensively studied and shows the high potential of commercial application, which may be attributed to two main reasons: (1) the affinity 
TABLE 1: Chemical composition of cement.

\begin{tabular}{lccccccc}
\hline $\mathrm{SiO}_{2}$ & $\mathrm{CaO}$ & $\mathrm{MgO}$ & $\mathrm{Al}_{2} \mathrm{O}_{3}$ & $\mathrm{Fe}_{2} \mathrm{O}_{3}$ & $\mathrm{SO}_{3}$ & $\mathrm{NaOeq}$ & Loss \\
\hline 19.98 & 61.86 & 2.02 & 4.61 & 3.07 & 4.43 & 0.68 & 0.9 \\
\hline
\end{tabular}

with cement hydration products at molecular scale and (2) a reasonable price resulting from industrial-scale production. It is generally accepted that NS is very effective in accelerating cement hydration at early age. Several authors [12-15] have studied the interaction between NS and cement in depth to advance the understanding of mechanisms of NS. The dominant mechanisms that have been proposed include (1) filling effect, as NS could act as fillers to densify the microstructure; (2) seeding effect, as NS has much large surface area than cement; the additional surface area could serve as site for the precipitation of calcium-silicate-hydrate (C-S-H) nucleus; (3) pozzolanic effect, as NS consumes calcium hydroxide to form additional C-S-H which would decrease the micro defects and make hydration products more homogeneous. These mechanisms may operate in parallel or in some complicated combination.

Given acceleration of hydration triggered by nano- $\mathrm{SiO}_{2}$ derived from seeding effect or filler effect, the proper dispersion is a critical problem for application and remains a big challenge. However, NS would inevitably agglomerate after mixing with cement and water, although it could be well dispersed in aqueous solution This is because the calcium ion leaching from dissolution of cement breaks the stabilization controlled by the electrical double layer. To mitigate the degree of agglomeration, some physical methods, such as ultrasonic waves method [16], have been adopted, but efficiency of these methods only exists in pure water and not in cement pore solution containing high concentration of different ion species. Surface modification of NS has been studied and proven to be one of the most accepted methods to improve the dispersion stability of NS in complicated condition [17], while few attentions have been paid to it in the area of cement and concrete. The polymer on the surface could provide the steric hindrance for nanoparticles to generate significant repulsive force. Owing to the application of polycarboxylate (PCE) in concrete technology for over decades, in present work [18], PCE was chosen to graft on the NS surface, forming a kind of core-shell nanoparticles (NS@PCE). As expected, NS@PCE are more stable in synthetic pore solution, compared with pristine NS.

From the aspect of cement chemistry, the surface state of NS@PCE is an important factor for their ability to accelerate cement hydration, because the surface state of NS@PCE may decide (1) their dispersed state in cement paste matrix associated with the total addition of surface area and (2) the rate of reaction with calcium hydroxide which is related to the total number of C-S-H nuclei. To further elucidate the relationship between the surface state of NS@PCE and accelerating effect and obtain an optimal dosage, in this paper, we conducted a series of experiments by isothermal conduction calorimetry, mechanical property measurement, $\mathrm{XRD}$, and SEM. The results show that the modified effect of NS@PCE has some new features, compared with that of pristine NS. Whether intended explicitly as a message to application of NS@PCE in cement and concrete area or not, the move highlighted the possibility of the surface modification of supplementary cementitious materials and their application.

\section{Materials and Methods}

\subsection{Materials}

2.1.1. Cement. Ordinary Portland cement compliant with the Chinese National Standard GB8076-2008 was used in this study. The oxide analysis of the cement was performed by X-ray fluorescence spectrometry (XRF, Thermo Fisher ARL). The compositions of the cement are listed in Table 1.

2.1.2. Nanoparticles. Colloidal NS used in this study was supplied by Suzhou Nano-dispersion Co., Ltd (China) with an initial solid content of $30 \%$ by mass. This NS was produced by a sol-gel technique, which was formed through hydrolysis and condensation of tetraethyl orthosilicate $\left(\mathrm{Si}\left(\mathrm{OC}_{2} \mathrm{H}_{5}\right)_{4}\right.$ $\left.+2 \mathrm{H}_{2} \mathrm{O} \stackrel{\mathrm{NH}_{3} \cdot \mathrm{H}_{2} \mathrm{O}}{\longrightarrow} \mathrm{SiO}_{2}+4 \mathrm{C}_{2} \mathrm{H}_{5} \mathrm{OH}\right)$. Note that although commercial NS was dispersed into aqueous dispersion as received, it still needed purification to remove unreacted tetraethyl orthosilicate, alcohol, ammonia, and other impurities as much as possible before chemical synthesis.

The synthesis procedures of NS@PCE have been demonstrated in previous work [18]. A series of NS@PCE were synthesized from silanized polycarboxylate superplasticizer and colloidal nano- $\mathrm{SiO}_{2}$ by "grafting to" method. Figure 1(a) demonstrates the chemical structure of NS@PCE. The particle size distribution of a series of PCE@PCE is determined by dynamic light scattering (ALV Co., CGS-3), as shown in Figure 1(b). Thermogravimetric analysis (TGA) quantified the content of PCE as the shell of NS@PCE using a thermal analyzer (TA Co., SDT-600). The shell-core ratio and hydrodynamic diameters of nanoparticles are listed in Table 2, which were calculated based on DLS and TGA experimental results.

\subsection{Methods}

2.2.1. Sample Preparation. To explore the effect of nanoparticles on cement hydration and mechanical property, cementitious paste mixtures with water to binder (cement + nanoparticles) ratio of 0.4 were prepared in this work. The dosages for each type of nanoparticles varied from $0 \%$ to $0.3 \%, 1 \%$, $2 \%$, and $3 \%$ by mass of the cement. For a series of NS@PCE, the nanoparticles mass is only considered as nano- $\mathrm{SiO}_{2}$ mass in NS@PCE; hence, at a fixed dosage, the relative number of nanoparticles would remain consistent when introduced to cement paste mixture. It is worth pointing out that the content 


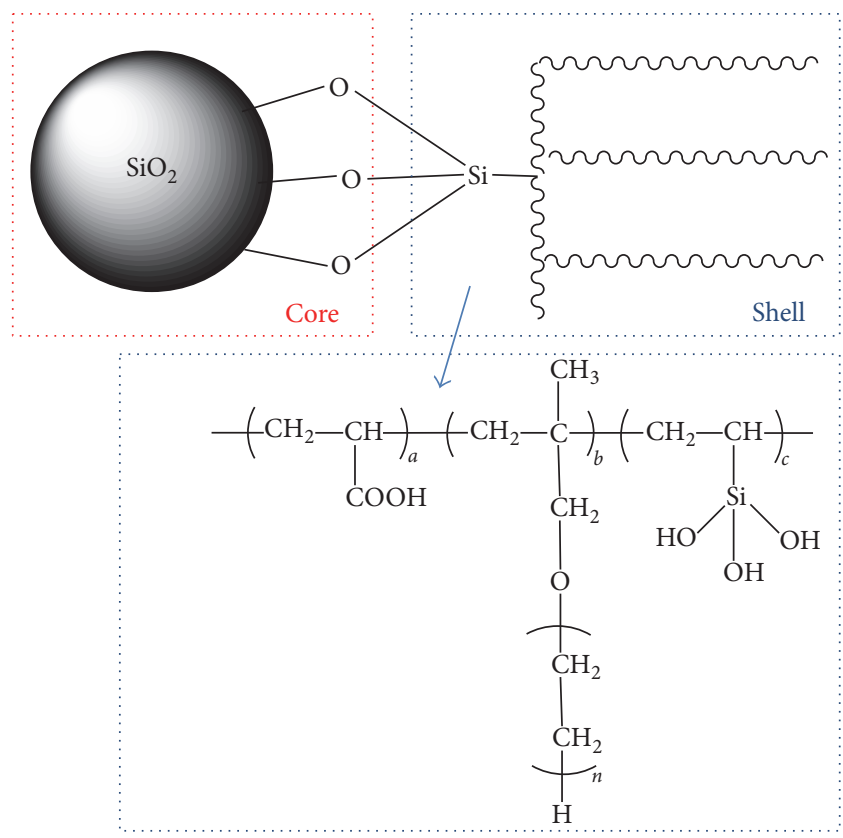

(a)

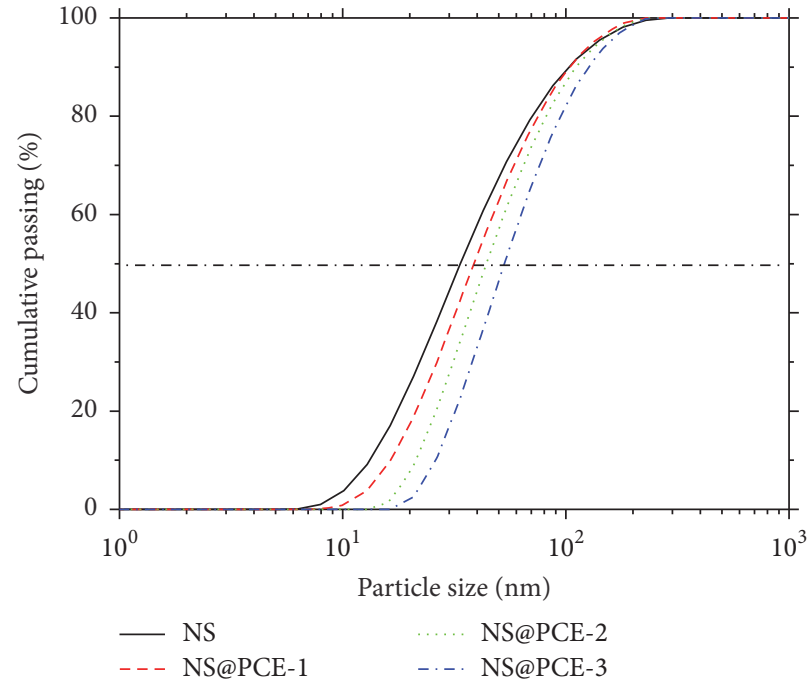

(b)

FIGURE 1: Schematic representation for NS@PCE: (a) chemical structure and (b) particle size distribution.

TABLE 2: The structural parameters of NS@PCE.

\begin{tabular}{lcc}
\hline Items & Shell-core ratio (wt\%) & $\begin{array}{c}\text { Hydrodynamic diameter } \\
\text { D50 }(\mathrm{nm})\end{array}$ \\
\hline NS & 0 & 33.84 \\
NS@PCE-1 & 7.52 & 38.64 \\
NS@PCE-2 & 9.99 & 44.48 \\
NS@PCE-3 & 17.35 & 53.48 \\
\hline
\end{tabular}

of PCE in NS@PCE can be determined by thermogravimetric analysis (TGA).

The mixing procedure is as follows: nanoparticle suspension and water were added to stainless steel mixer; cement was gradually added over a time span of $30 \mathrm{~s}$ at rotating rate of $60 \mathrm{rpm}$. After a $15 \mathrm{~s}$ interval, the cement paste was further mixed for another $60 \mathrm{~s}$ at $500 \mathrm{rpm}$ and $60 \mathrm{~s}$ at $1500 \mathrm{rpm}$.

2.2.2. Rate of Cement Hydration. The influence of NS@PCE on the rate of cement hydration was tracked by isothermal conduction calorimetry. An isothermal calorimetry system (TA Co., TAM Air) was used to determine the heat evolved during the first $72 \mathrm{~h}$ at a constant temperature of $25^{\circ} \mathrm{C}$. The thermal power and energy were used to assess reaction kinetics and the cumulative heat release of cementitious mixture. The paste of $10 \mathrm{~g}$ was placed on ampoules inserted into the instrument within $5 \mathrm{~min}$ after initial cement and water contact. The heat data of hydration system was recorded every $60 \mathrm{~s}$ during test procedure.

2.2.3. Compressive Strength. Compressive strength of the composites was measured as described in ASTM C109. Cubic specimens for all mixtures (blank cement pastes, pastes containing NS, and pastes containing NS@PCE) were cast and stored in sealed condition at $25^{\circ} \mathrm{C}$; after $12 \mathrm{~h}$ they were demolded and immersed in saturated limewater. Measurements were taken at $12 \mathrm{~h}, 24 \mathrm{~h}, 48 \mathrm{~h}$, and $72 \mathrm{~h}$. The strength value reported is the average of three replications.

2.2.4. XRD. X-ray diffraction analyses (XRD) were carried out on powdered paste mixtures after isopropyl alcohol solvent exchange at each desired age using a Bruker D8 Advance diffractometer in a $\theta-\theta$ configuration using $\mathrm{Cu}-$ $\mathrm{K} \alpha$ radiation. The scanning range was $5 \sim 70^{\circ} \mathrm{C}(2 \theta)$ with a scanning rate of $0.02^{\circ} \mathrm{C} / \mathrm{s}$.

2.2.5. SEM. The morphologies of the samples were examined by Quanta 250 Field Emission Scanning Electron Microscope (FEI, Hillsboro, OA, USA) using a FEI 3D microscope. The vacuum oven-dried sample was coated with $15 \mathrm{~nm}$ of gold to make it conductive before observation. 


\section{Results and Discussion}

\subsection{Cement Hydration}

3.1.1. Stages of Cement Hydration. To better understand the influence of nanoparticles on the properties of the cementitious materials, it is essential to have a basic comprehension of the kinetic mechanisms for cement hydration. According to the classical theory, a typical cement hydration process can be divided into five stages, that is, the initial reaction period, the induction period, the acceleration period, the deceleration period, and the decline period, as shown in Figure 1. The initial hydration (Stage I) exothermic peak is the result of the wetting of granules surface, the fast dissolving of the hydrous phases, and the precipitation of ettringite due to the fast reactivity of the aluminates and calcium sulfate. The sharp peak is followed by the rapid decline; then an induction period (Stage II) occurs with a low heat flow rate. The mechanism of the induction period is still a subject of considerable debate. Compared to the traditional inhibiting layer theory, recent experimental evidences manifest that geochemistry dissolution theory seems a more reasonable explanation for the induction period [14]. The acceleration period (Stage III) presents an intensely exothermic rate, which is the result of the nucleation and growth of C-S$\mathrm{H}$. After the main heat evolution peak, there is an obvious shoulder peak that comes from the transformation of ettringite phase to AFm phase. At the end of acceleration period, the deceleration period (Stage IV) occurs with heat evolution rate dropping. While it is often assumed that the transition to diffusion rate control is responsible for this period, a new perspective was proposed as another interpretation that the inevitable impingement of region of growing hydration product reduced the surface available for nucleation and growth [19]. Finally, the hydration process steps into the decline period when heat release decreases to nearly zero (Stage V). The low activity is due to the slow diffusion of species in the hardened structure.

For further analysis of the influence of NS@PCE on cement hydration, in the subsequent presentation of the results, three points would be extracted from heat flow profile curves, that is, A, B, and C (Figure 2). A is the start point of acceleration period and also the end of induction period, $\mathrm{B}$ is the main peak point in acceleration period, and $C$ is the shoulder peak. Heat flow value of these points and the time value at these points would be observed and correlated with characteristic parameters of NS@PCE.

3.1.2. Effect of Nanostructure of NS@PCE. Figure 3 shows the measured heat flow profiles of cement pastes prepared with different structures of NS@PCE at a dosage of $0.3 \mathrm{wt} \%$. In general, it can be seen that three types of NS@PCE exhibit different influence on heat evolution. As noted by the upward shift of the rate curves, the rate of hydration increases after NS@PCE-1 and NS@PCE-2 added, while for NS@PCE-3, it only has a slight impact on cement hydration, the same as pristine NS. As reported in previous work [18], with shell-core ratio increasing, NS@PCE appeared to have

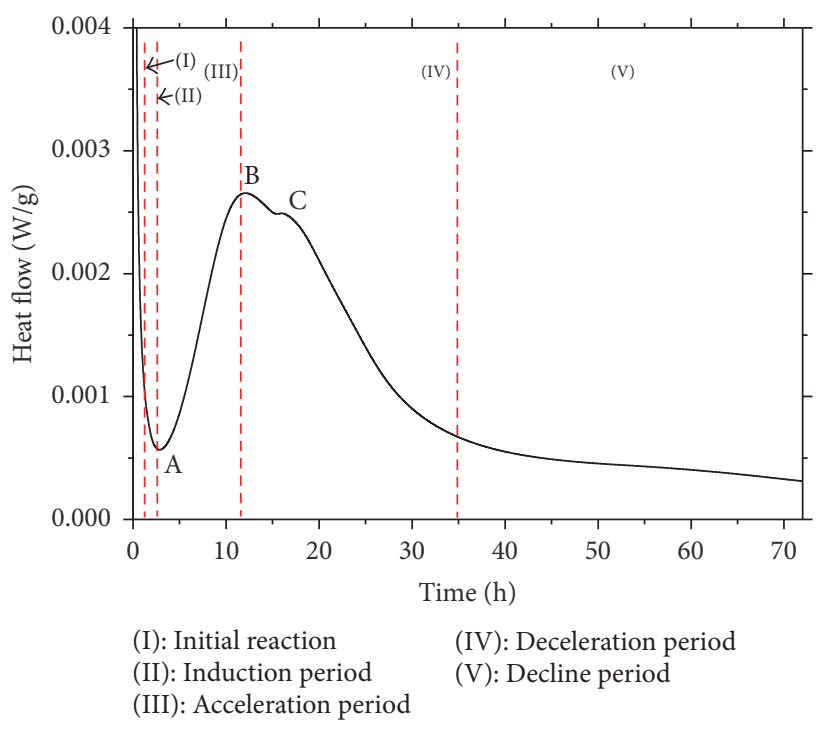

FIgURE 2: Typical heat flow profile of cement hydration.

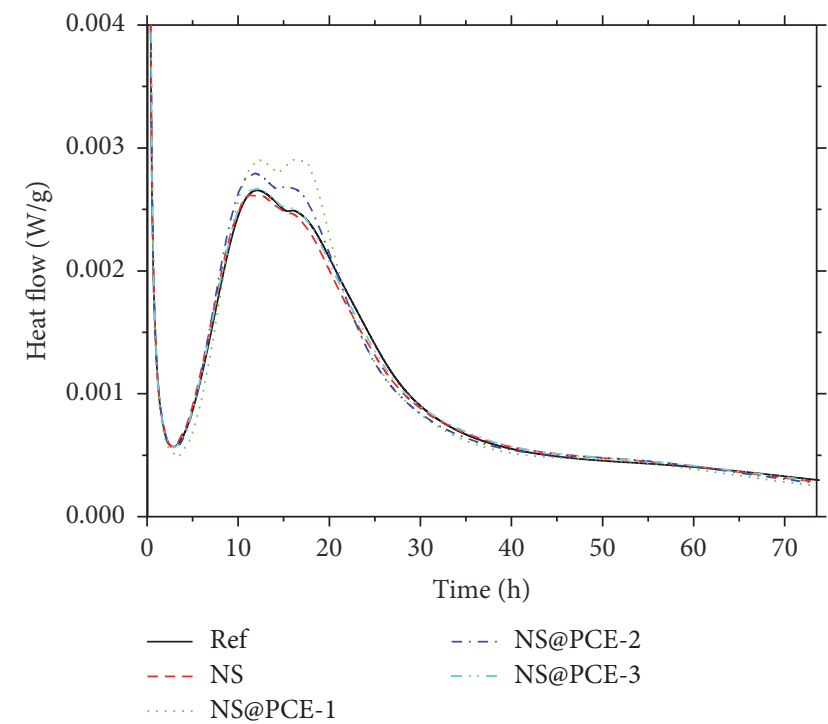

Figure 3: Measured heat flow profiles for cement pastes with nanoparticles at $0.3 \mathrm{wt} \%$.

stronger dispersion stability in synthetic cement pore solution. Therefore, among a series of NS@PCE, NS@PCE-3 with highest shell-core ratio may appear to have best dispersion state in cement matrix; it can provide the largest surface area for the nucleation and growth of C-S-H. However, this deduction does not conform to the experimental result as shown in Figure 3. It means that, for a series of NS@PCE, the discrepancy in modification effect could not be explained by different dispersion states of nanoparticles in cement paste matrix, and a possible mechanism would be further elucidated in Section 3.4.

The higher the dosage of nanoparticles is, the more difficult it is for them to disperse in the matrix. This indicates that the dispersibility may become a dominant factor for 


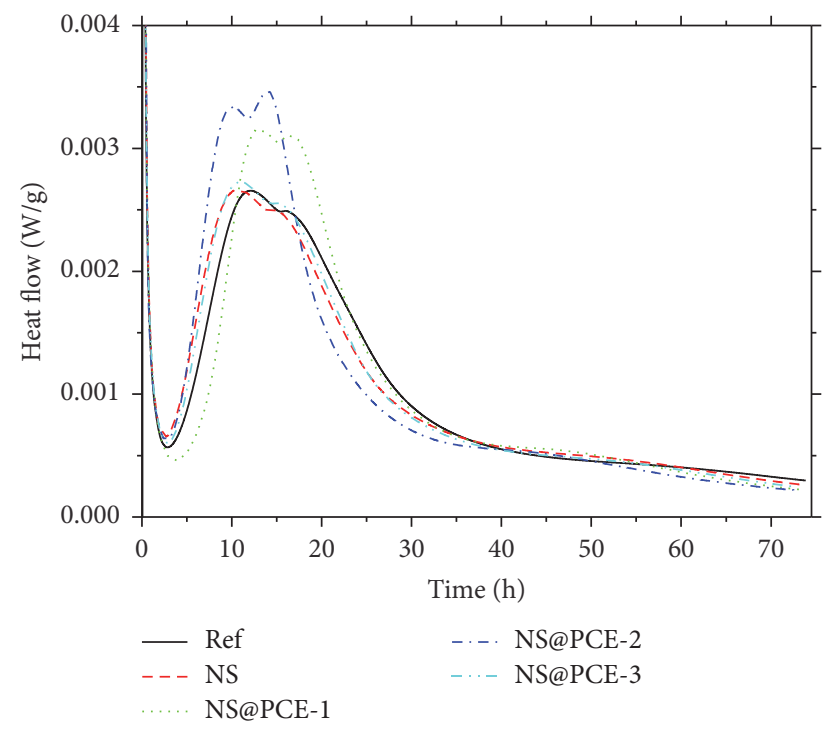

FIgURE 4: Measured heat flow profiles for cement pastes with nanoparticles at $1 \mathrm{wt} \%$.

enhancing cement hydration at a higher dosage. To assess the sensitivity of effectiveness of NS@PCE to dosage, a higher dosage was carried out. The measured heat flow profile of cement pastes in the presence of various nanoparticles at a dosage of $1 \mathrm{wt} \%$ is shown in Figure 4. As noted in Figure 4, the NS@PCE with different structures have different influence on the heat evolution. To be more specific, NS@PCE-2 is the most effective one in enhancing cement hydration, as characterized by two aspects: (a) the initial time of acceleration period and (b) amplitude of the main heat peak. An obvious acceleration effect is also obtained by NS@PCE-1, although it is not so strong as NS@PCE-2, while for NS@PCE-3 and pristine NS, they only exhibit a slight disturbance. It is also very interesting that, in the heat flow profile of NS@CPE-2added cement paste, the shoulder peak appears first; this is not conformed to the traditional curve of cement past where shoulder peak always follows the main peak [20].

According to the experimental results above, one can see that modification effects of nanoparticles could vary widely, even when they have similar particle size distributions and are added into cement pastes at the same dosage. This phenomenon should be related to the specific structures of nanoparticles or, in other words, the surface chemical properties of nanoparticles. Then, it is necessary to understand the relationship between the structures of nanoparticles and modification effects of nanoparticles on cement hydration. To further quantify the influence of NS@PCE in acceleration period, as mentioned earlier, some eigenvalues are extracted from heat flow profile curves to correlate with shell-core ratio of NS@PCE.

Figure 5(a) shows the evolution of $T_{\mathrm{A}}, T_{\mathrm{B}}$, and $T_{\mathrm{C}}$ as a function of shell-core ratio. As shown in Figure 5(a), $T_{B}$ and $T_{\mathrm{C}}$ are sensitive to the change of shell-core ratio, while $T_{\mathrm{A}}$ is not. For $T_{\mathrm{B}}$ and $T_{\mathrm{C}}$, at a certain ratio of 9.99 (NS@PCE-2), they reach a maximum which is higher than the reference time from cement pastes without nanoparticles added. However, at other ratios, both $T_{\mathrm{B}}$ and $T_{\mathrm{C}}$ are lower than the reference. This indicates that only a moderate shell-core ratio could shorten the initial time of acceleration period. Figure 5(b) illustrates the correlation between the shell-core ratio and characteristic heat flow value at peak. As noted by Figure 5(b), $H_{\mathrm{A}}$ keeps a stable fluctuation as shell-core ratio increases. It is also clearly seen that $H_{\mathrm{B}}$ and $H_{\mathrm{C}}$ increase with the increase in shell-core ratio expect for the values at a ratio of 17.35. It means that the heat flow at peak could be enforced by rising shell-core ratio until reaching a threshold. A possible mechanism would be further discussed in Section 3.4. In addition, the analysis suggests that the impact of NS@PCE on cement hydration could be quantified very well by shell-core ratio, which is able to reflect surface properties of NS@PCE at some extent.

3.1.3. Effect of Dosages. Nanoparticles have been found to be effective in the stimulation of nucleation processes during the early cement hydration period [21]. The effect (socalled filler effect) is usually attributed to the provision of additional surface area by nanoparticles, of which particle size is approximately three orders of magnitude less than that of cement. In the traditional theoretical analysis, nanoparticles are considered to disperse in cement paste matrix in the form of monoparticle. Thus, the higher dosage was added, the larger surface area was got. However, if the serious agglomeration of nanoparticles appears, the dosage is no longer a scaling factor that can describe the change in solid surface area induced by nanoparticles addition.

To observe the sensitivity of modification effect of nanoparticles to the dosage, the dosages of $0.3 \%, 1 \%, 2 \%$, and $3 \%$ were investigated. The results of pristine NS are presented in Figure 6. As shown in Figure 6, with the increase of dosage, the main hydration peak is shifted leftwards and the height of the curve is shifted upwards. For a low dosage of $0.3 \%$, the modification effect is not very significant. For a high dosage of $3 \%$, the change in the hydration curve is similar to the case of dosage of $2 \%$. It may indicate that the agglomerations of nanoparticles appeared, which means the rise of surface areas could stay almost unchanged even if more nanoparticles were added to cement paste; thus hydration process is less responsive to the dosage increases.

According to the previous experimental results (Figure 4), among a series of NS@PCE, NS@PCE-2 is most effective in accelerating cement hydration at a dosage of 1\%. Here, NS@PCE-2 (NP) was chosen to further test its modification effect at higher dosages. Figure 7 shows the measured heat flow profiles for NS@PCE-2-added cement pastes at different dosages. It is noted that, in general, an increase in the dosage acts to increase the hydration process. This increase manifests as an upshift of the heat flow curve. To be more specific, for a low dosage of $0.3 \%$, the modification effect is unapparent, while it becomes significant at higher dosages. The accelerating effect seems no longer responsive to the dosage when the dosage exceeds a threshold, as compared with the curves at the dosage of $2 \%$ and that of $3 \%$. What is more, compared with case of NS, it is interesting that there is hardly left-shift phenomenon presented in the curves. 


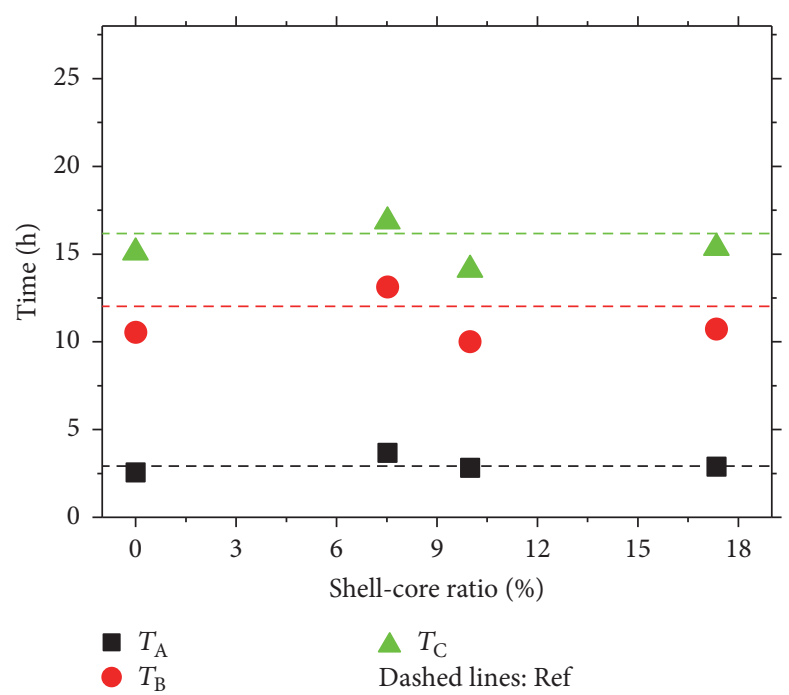

(a)

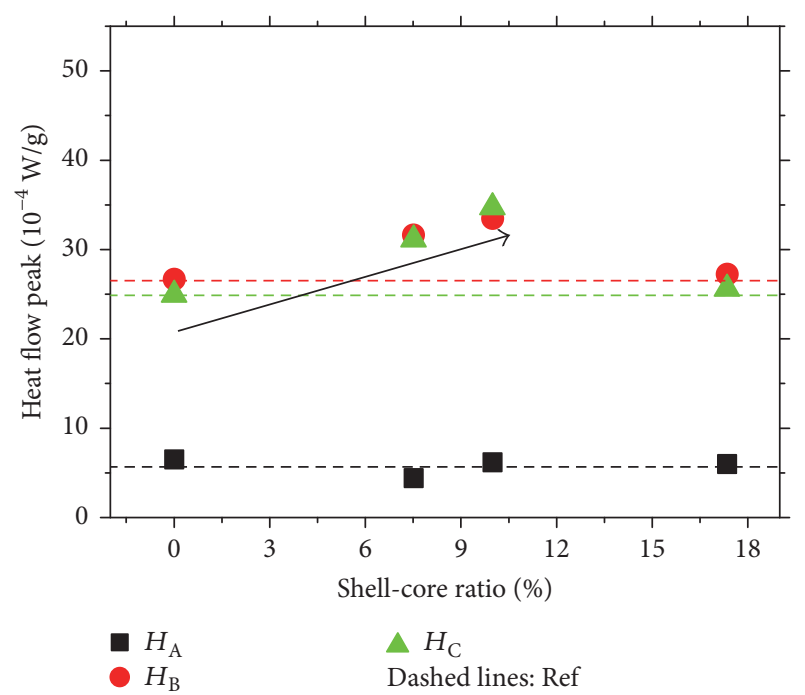

(b)

FIGURE 5: The relationship between the shell-core ratio and parameters corresponding to the measured heat flow profile at 1 wt\%: (a) characteristic time at peak and (b) characteristic heat flow at peak.

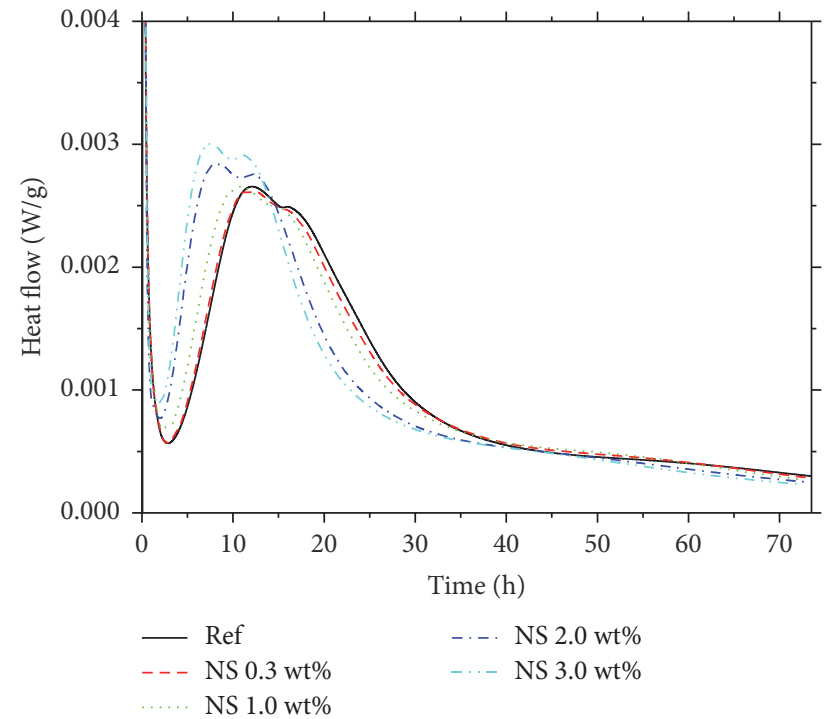

FIGURE 6: Measured heat flow profiles for NS-added cement pastes at different dosages.

To get a more detailed observation, as mentioned before, some characteristic values were extracted from heat flow profiles. Here, we utilize these extracted parameters to correlate with dosages. Figure 8 shows the evolution of $T_{A}, T_{B}$, and $T_{\mathrm{C}}$ as a function of dosages in the case of pristine NS and NP. For the case of NS (Figure 8(a)), it can be seen that there is clearly a linear regression between the dosage and $T_{\mathrm{A}}$ (or $T_{\mathrm{B}}$ or $T_{\mathrm{C}}$ ). The slope of the curve associated with $T_{\mathrm{B}}$ ( or $T_{\mathrm{C}}$ ) is greater than that of the curve associated with TA. This suggests that $T_{\mathrm{B}}$ or $T_{\mathrm{C}}$ is severely affected by dosages. Figure 8(b) illustrates the case of NP. From Figure 8(b), it is noted that $T_{\mathrm{A}}$ is inactive to the change in dosages, as opposed

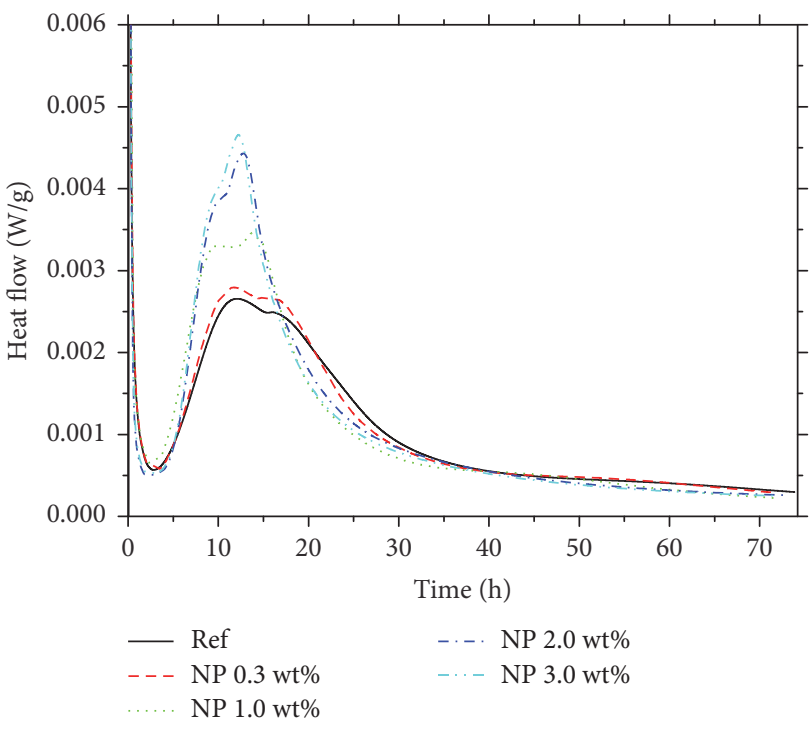

FIGURE 7: Measured heat flow profiles for NS@PCE-2-added cement pastes at different dosages.

to $T_{\mathrm{B}}$ and $T_{\mathrm{C}}$. The trends of $T_{\mathrm{B}}$ and $T_{\mathrm{C}}$ are nearly identical; that is, they drop dramatically as dosage increases until stopping at a platform. This observation is unsurprising if we consider the hypothesis that the agglomeration of nanoparticles always existed at high dosage which makes the increase in the dosage no longer contribute to the growth in the total surface area of hydration system.

Figure 9 exhibits the relationship between the dosage and characteristic heat flow in the case of pristine NS and NP. For the case of NS, as shown in Figure 9(a), all of the three characteristic heat flows have a similar trend that escalates as a function of the dosage. They are all higher than the 


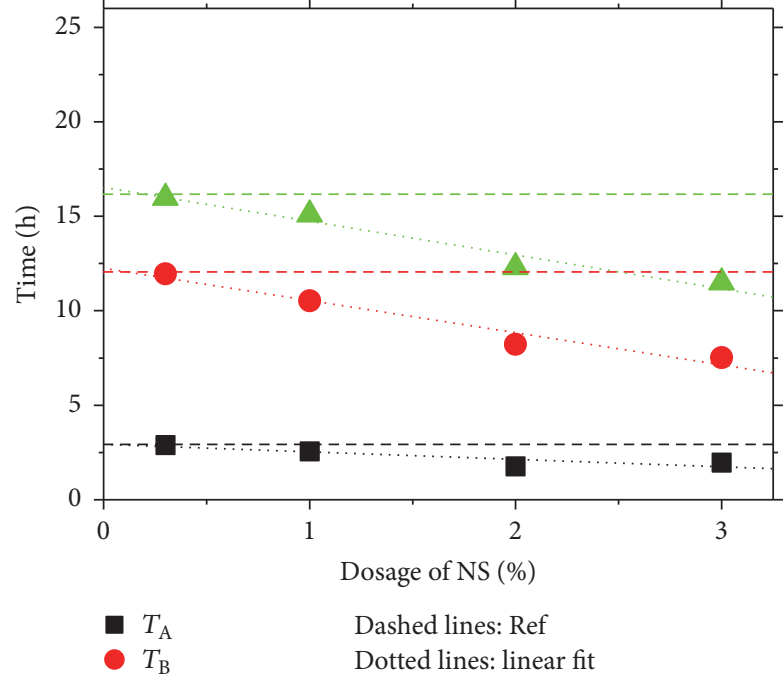

(a)

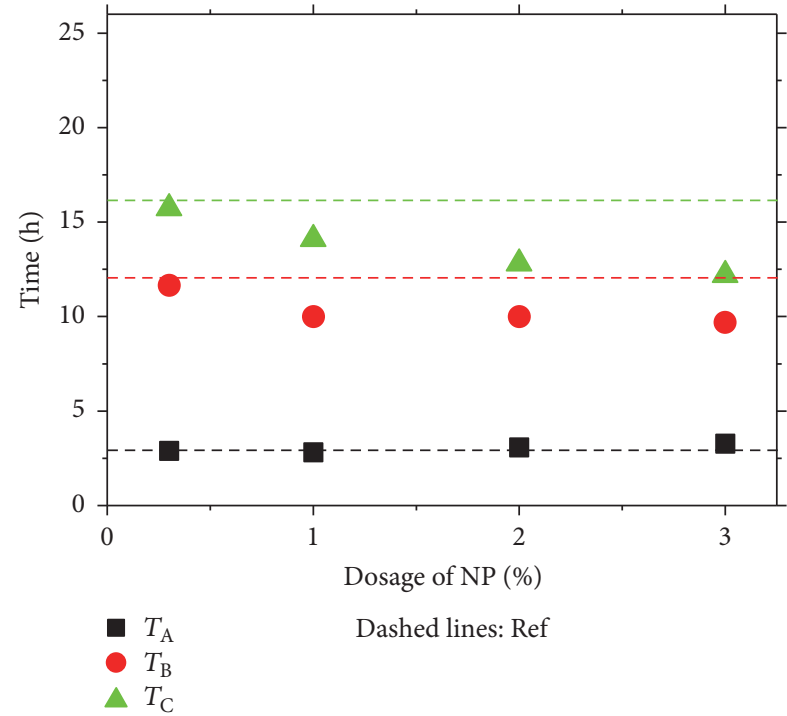

(b)

FIGURE 8: The relationship between dosage and characteristic time at peak corresponding to the measured heat flow profile: (a) NS and (b) NP.

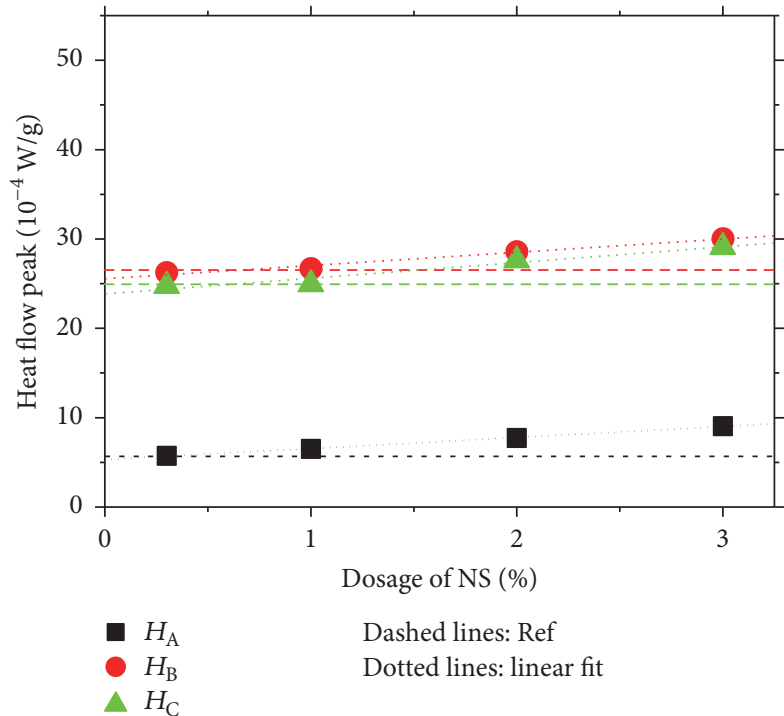

(a)

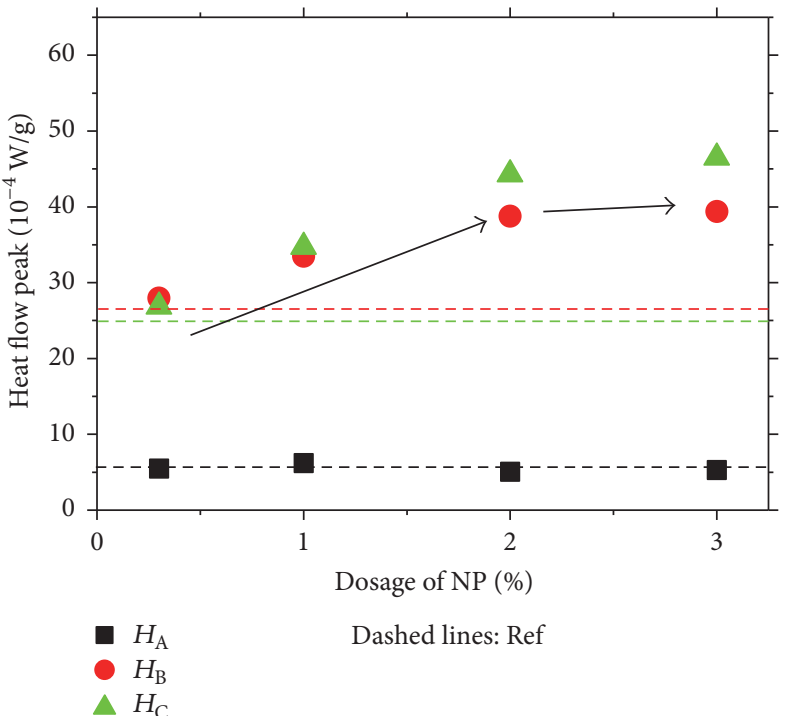

(b)

FIGURE 9: The relationship between dosage and characteristic heat flow at peak corresponding to the measured heat flow profile: (a) NS and (b) NP.

value of the reference cement pastes, if the dosage was higher than $1 \%$, while for the case of NP, as noted in Figure 9(b), some different features could be found. For example, unlike $H_{\mathrm{A}}$ shown in Figure 9(a), $H_{\mathrm{A}}$ in Figure 9(b) seems more insensitive to the change in dosage. What is more, with the dosage rising, the fluctuations of $H_{\mathrm{B}}$ and $H_{\mathrm{C}}$ are more apparent. The linear regression seems to only exist before the dosage of $2 \%$. These observations suggest that the physical or the chemical process of NS and NP may be controlled by different mechanisms, as the dosage increases.

\subsection{Compressive Strength}

3.2.1. Effect of Nanostructure of NS@PCE. Compressive strength is one of the most important mechanical properties of cementitious materials. Figure 10 shows the relative compressive strength evolution for cement paste prepared with four different types of nanoparticles. As noted by Figure 10, in general, regardless of the curing ages, all kinds of nanoparticles could produce an increase in the compressive strength. This effect is more prolific in the samples with NS@PCE-2. 


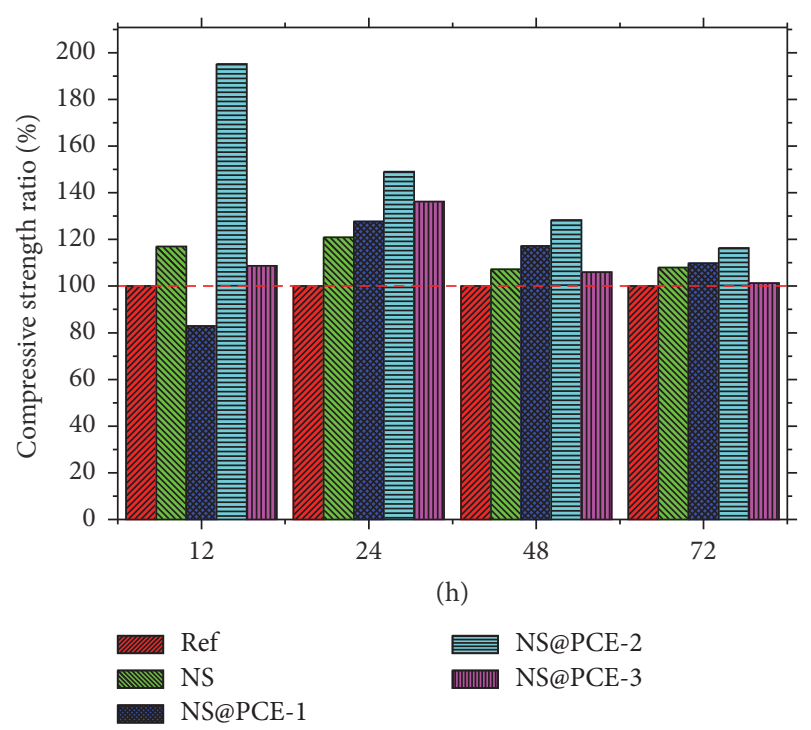

FIGURE 10: Relative compressive strength for cement pastes with nanoparticles at $1 \mathrm{wt} \%$.

For example, the increase extent is as high as $125 \%$ at the age of $12 \mathrm{~h}$ and remains the highest at all ages. This observation may be partially ascribable to the assumption that NS@PCE2 has the best-dispersed state in cement pastes matrix. In addition, the difference in enhancing compressive strength diminishes over time. Another interesting observation is that the strength of NS@PCE-1-added sample is lower than the reference at the age of $12 \mathrm{~h}$. It is reported that NS addition would lead to high-polymerized C-S-H gels [22, 23]. For a series of NS@PCE, at specific time, they may produce C-S-H gels with different quantity or quality, which may be another mechanism accounting for compressive strength enhancement.

3.2.2. Effect of Dosage. To reveal the influence of the dosages of NS/NS@PCE-2 (NP) on the relative compressive strength, cement pastes with four dosages of $0.3,1 \%, 2 \%$, and $3 \%$ were measured. Figure 11 shows the results of samples with NS. From Figure 11, it is clearly seen that the relative compressive strength increases as a function of the dosage in all curing ages, with the maximum values produced by the dosage of $3 \%$. This consequence is confirmed to other similar researchers reported by Nazari and Riahi [24] and Singh et al. [25]. It could be explained by the so-called filler effect or seeding effect; that is, additional surface area could offer more nucleation sites. However, the prerequisite for this interpretation is the ideal monodispersion of nanoparticles. Compared with the result of $72 \mathrm{~h}$ and that of $12 \mathrm{~h}$, we can find that the improvement in strength is toned down over time. This may be due to the fact that the side effects of the formation of agglomeration become more obvious at later age including the following: (a) agglomeration would develop into the weakened zone which also generates many new interfacial transition zones [26] and (b) agglomeration can decrease active surface which would reduce the rate of the pozzolanic reaction.

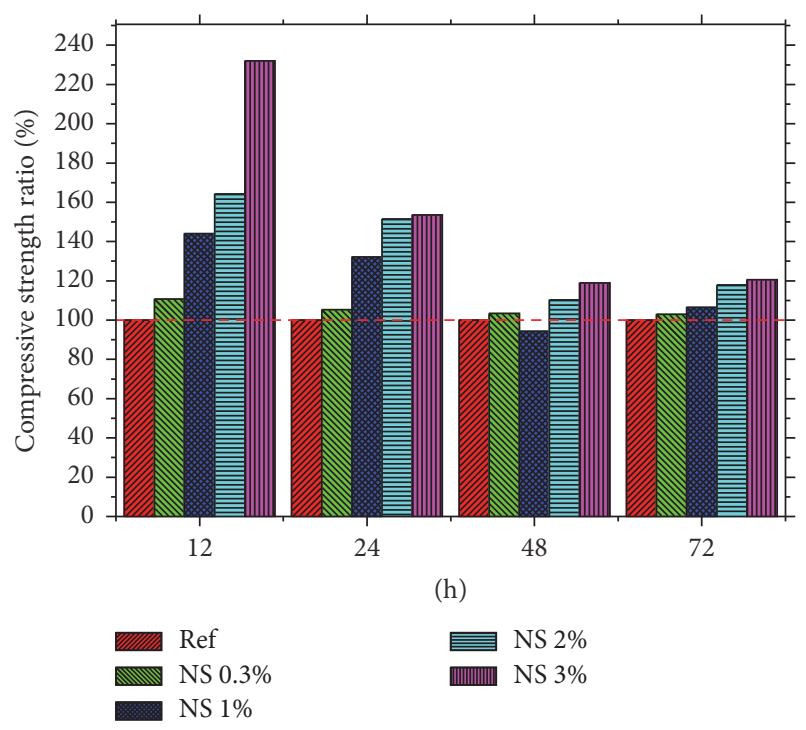

FIGURE 11: Relative compressive for NS-added cement pastes at different dosages.

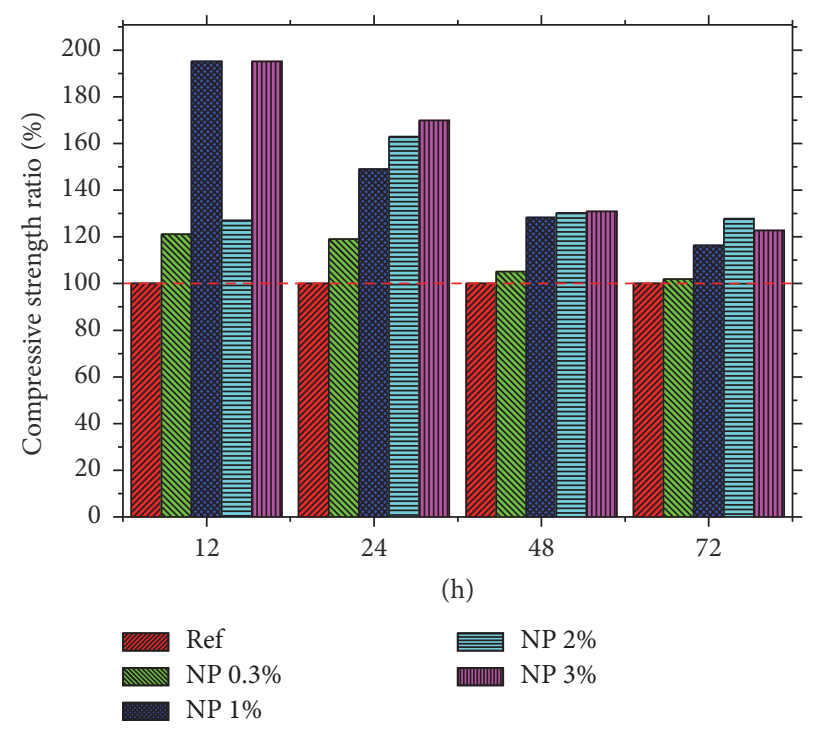

FIGURE 12: Relative compressive strength for NS@PCE-2-added cement pastes at different dosages.

The trends in strength development of samples with NP are shown in Figure 12. In general, apart from the result at the age of $12 \mathrm{~h}$, the relative strength of samples increases with the dosage increasing up to $2 \%$, while there is no appreciable disparity between the dosage of $2 \%$ and that of $3 \%$. At the age of $12 \mathrm{~h}$, the dosage of $1 \%$ has a similar improvement effect compared with that of $3 \%$. This may be due to the fact that, at this curing time, NP fortunately achieves a better balance between lowering the agglomeration and enhancing the pozzolanic reaction. According to the previous research [18], it is rationalized that NP would have a better dispersion state in cement pastes matrix than NS. Then higher strength would be obtained by samples with NP at the same dosage. 


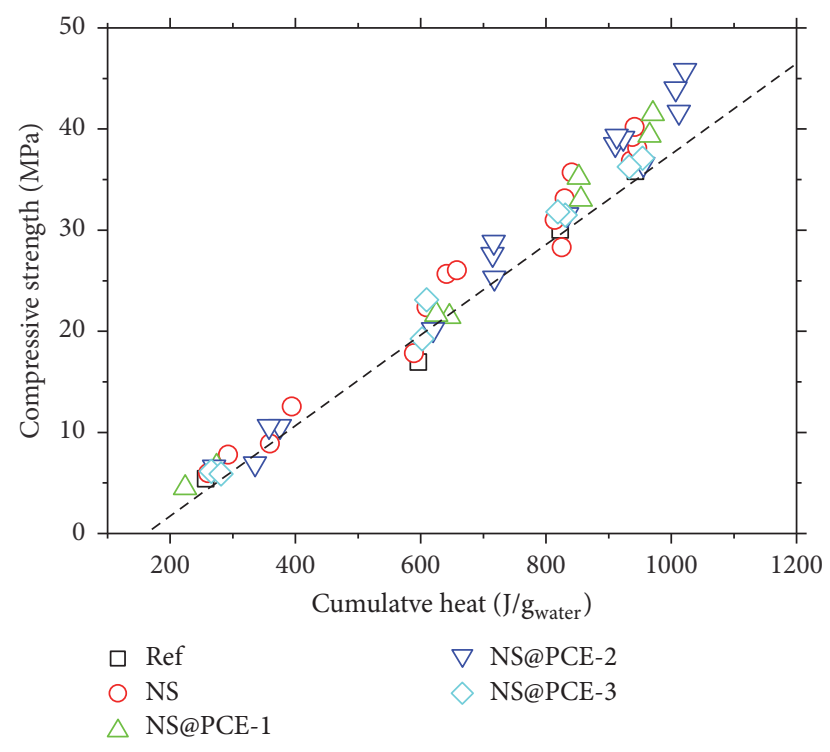

FIGURE 13: Measured compressive strength versus cumulative heat release, normalized by initial water content.

This speculation could be confirmed by comparing the results in Figures 11 and 12. Based on these results, it can be concluded that NP could enhance the strength of cementbased materials at lower dosage, especially at the early age, compared with pristine NS.

\subsubsection{Relationship between Compressive Strength and Cumu-} lative Heat. It is attractive to acquire the mechanical property development by adopting the date from calorimeter isothermal measurement. Some researchers [27-29] unambiguously showed that there is a strong correlation between the heat evolution and compressive strength in the hydration system with supplementary materials, such as fly ash and limestone. To verify this correlation in hydration system with nanoparticles, the relationship between compressive strength and cumulative heat releases is explored as shown in Figure 13. All the hydration heat data are extracted from the experimental results in Section 3.1. It should be noted that the measured heat is normalized by initial mixture water, which is a sign of the initial space surrounded by the cement grain and would be filled by hydration product over time. As noted in Figure 13, a reasonable correlation is achieved, where the majority of data points fall into the acceptable bound of the linear best fit line. No matter data come from NSadded sample or NS@PCE-added sample, they present a lower deviation when cumulative heat value is below $600 \mathrm{~J} / \mathrm{g}$. It is meaningful to get the information of linear correlation, because it suggests that the mechanical properties of samples with NS or NP can be inferred by heat evolution data. This is also a worthwhile complement to the research of the nanoparticles added hydration system.

3.3. Microstructure. To get some more details about modification effect, X-ray diffraction analysis was carried out to measure samples with $1 \mathrm{wt} \% \mathrm{NS}$ and $1 \mathrm{wt} \% \mathrm{NP}$ at the ages of

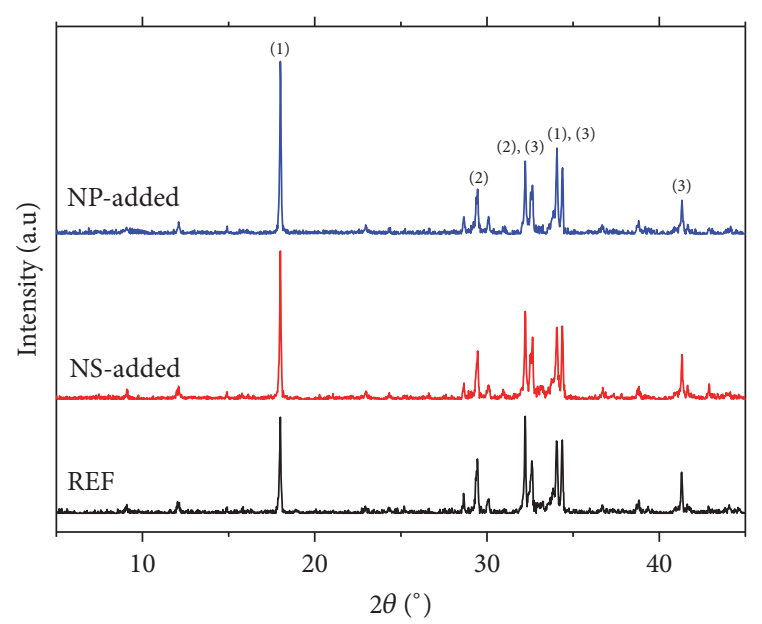

(1): $\mathrm{Ca}(\mathrm{OH})_{2}$

(2): $\mathrm{C}_{3} \mathrm{~S}$;

(3): $\mathrm{C}_{2} \mathrm{~S}$

FIGURE 14: XRD patterns of cement pastes with nanoparticles at $6 \mathrm{~h}$.

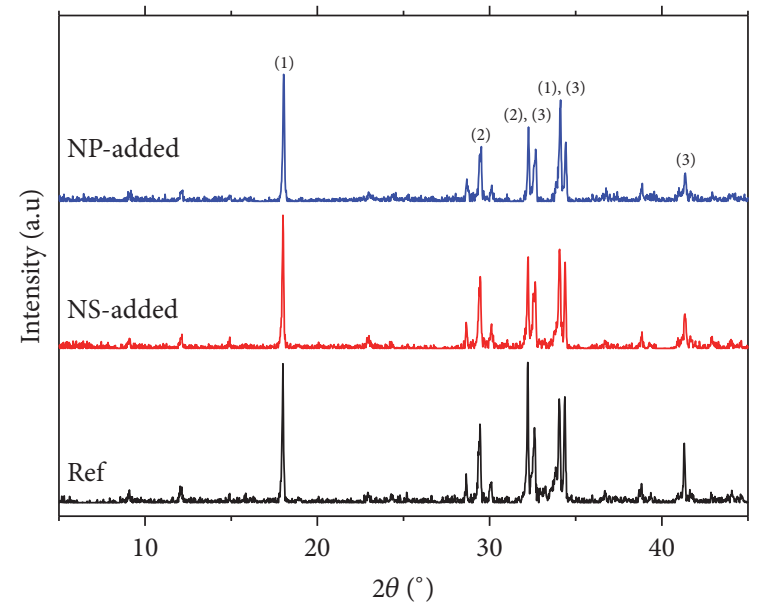

(1): $\mathrm{Ca}(\mathrm{OH})_{2}$

(2): $\mathrm{C}_{3} \mathrm{~S}$;

(3): $\mathrm{C}_{2} \mathrm{~S}$

FIGURE 15: XRD patterns of cement pastes with nanoparticles at $12 \mathrm{~h}$.

$6 \mathrm{~h}$ and $12 \mathrm{~h}$, and the results are shown in Figures 14 and 15, respectively. The main crystalline phases are identified and marked including calcium hydroxide $(\mathrm{CH})$, dicalcium silicate $\left(\mathrm{C}_{2} \mathrm{~S}\right)$, and tricalcium silicate $\left(\mathrm{C}_{3} \mathrm{~S}\right) . \mathrm{C}_{2} \mathrm{~S}$ and $\mathrm{C}_{3} \mathrm{~S}$ are the two most important mineral phases of unhydrated cement. The source of $\mathrm{CH}$ is same for all samples as generated by the hydration process of cement. However, the final amount of $\mathrm{CH}$ is not just influenced by hydration process. For reference sample, the amount of $\mathrm{CH}$ is only controlled by hydration process of $\mathrm{C}_{2} \mathrm{~S}$ and $\mathrm{C}_{3} \mathrm{~S}$, while for the samples with NS or $\mathrm{NP}$, another chemical process, that is, pozzolanic reaction between nanoparticles and $\mathrm{CH}$, should be considered because this reaction consumes $\mathrm{CH}$. It has been documented that $\mathrm{CH}$ content disparity between NS-added sample and reference would first get a maximum point within few hours [26]. This 


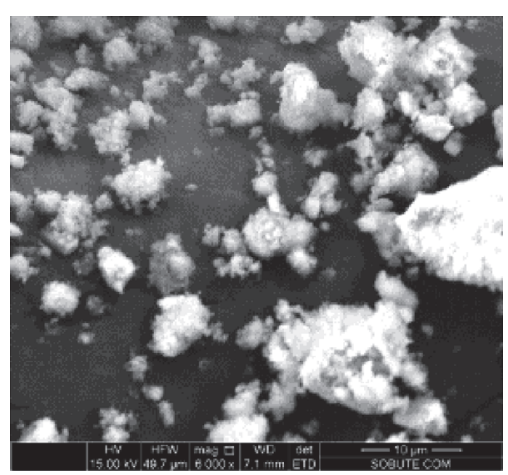

(a)

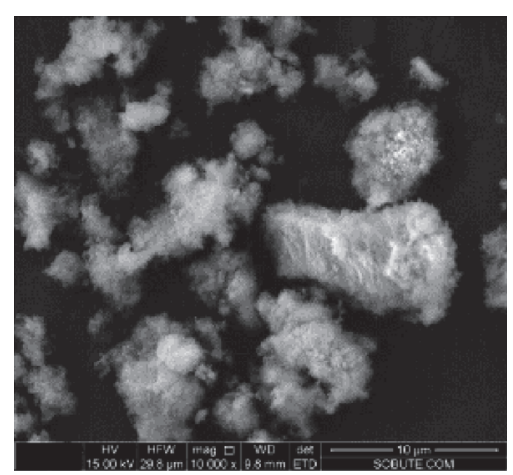

(b)

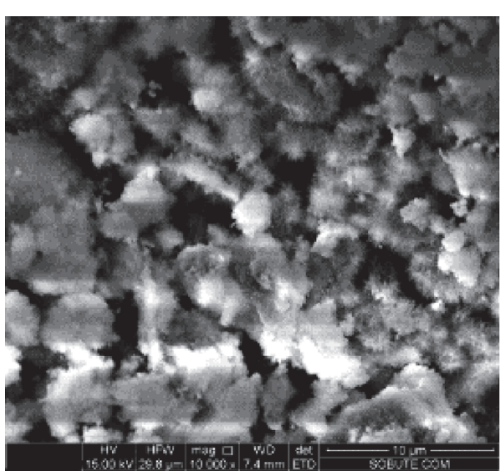

(c)

FIgURE 16: SEM images of cement pastes with nanoparticles at $6 \mathrm{~h}$ : (a) Ref, (b) NS, and (c) NP.

is due to the hydration acceleration effect of NS. After the maximum point, the $\mathrm{CH}$ content disparity would decrease steadily due to the effect of pozzolanic reaction. These trends are also observed in NP-added samples as noted in Figures 14 and 15. As shown in Figure 14, at $6 \mathrm{~h}, \mathrm{CH}$ peak in the NP-added samples is more intense than that in other samples. This indicates again that both NS and NP could accelerate the hydration and the effect of NP could be more pronounced. For three type samples at $12 \mathrm{~h}$ (Figure 15), there is no significant difference in the $\mathrm{CH}$ peak. It suggests that pozzolanic reaction has been shown to be more apparent in the samples with NS or NP. From the fact that $\mathrm{CH}$ content in $\mathrm{NP}$-added sample is higher than that in NS-added sample at $6 \mathrm{~h}$ while they are approximately equal at $12 \mathrm{~h}$, we can infer that the NP may have a greater ability to consume $\mathrm{CH}$ by pozzolanic reaction at later age.

Since main hydration product C-S-H is hard to be detected by XRD due to its amorphous character, it can be identified by SEM. The morphology image of NPadded samples at $6 \mathrm{~h}$ was measured by SEM as shown in Figure 16 and compared with that of reference and NSadded samples. It can be seen from Figure 16(a) that irregular needle-like C-S-H appeared on the surface of cement grain resulting from the hydration of $\mathrm{C}_{2} \mathrm{~S}$ and $\mathrm{C}_{3} \mathrm{~S}$. The amount of needle-like C-S-H improved after NS was added as shown in Figure 16(b). For sample with NP, more needle-like C-S-H can be found and some cement grains' surfaces have been filled with these products (see Figure 16(c)). The results further verify the discussion mentioned before demonstrating that NP could boost up cement hydration more effectively than NS.

\subsection{Discussion}

3.4.1. Seeding Effect. Fine particles are known to accelerate cement hydration. It is generally accepted that this acceleration effect has been attributed to additional surface which provides extra nucleation sites for $\mathrm{C}-\mathrm{S}-\mathrm{H}$ phases. In particular, as shown in Figures 17(a) and 17(b), in blank cement paste, it is usually hypothesized that the nucleus of C-S-H can only grow on the surface of cement grains, while, in the cement with NS, expect for cement grain surface, the nanoparticle surface also can be the place where nucleus precipitated (see Figures 17(c) and 17(d)). Normally, the diameter of nanoparticle is about three orders of magnitude smaller than that of cement grain; therefore total surface area for nucleation sites would increase with the dosage of nanoparticles increasing. Oey et al. [30] and Costoya [31] have proposed that the seeding effect is proportional to the total surface of area. In this study, characteristic heat flow parameters are found to be in linearity with the dosage of NS (see Section 3.1.2); therefore it seems that seeding effect is still suitable for explaining the phenomenon of hydration acceleration by NS.

\subsubsection{Relationship between Dispersion, Nucleation, and Sur-} face Properties of Nanoparticles. According to the seeding effect theory, additional surface areas are responsible for acceleration effect, so the dispersion in cement matrix is the key problem for the application of nanoparticle. For NS, it is well monodispersed in water with a $\mathrm{PH}$ value of 7-9 by reason of hydrogen bonding between the surface silanol groups and the water molecules resulting in the formation of a water layer around nanoparticles [32]. Meanwhile in the solution with $\mathrm{PH}$ in excess of 12 , the nanoparticles acquire a negative charge surface through partial deprotonation; then the hydrolyzed surface would produce electrostatic force to overcome the attractive force between nanoparticles. In cement pore solution, the dispersion issue would become more complicated with the presence of various ions such as $\mathrm{Ca}^{2+}, \mathrm{Na}^{+}$, and $\mathrm{K}^{+}$. Among these cations, calcium ion is the most important factor affecting the stability of particles. Calcium ions of cement pore solution always present near the portlandite saturation point; in such concentration, calcium ion would affect the stability of NS by reducing the electrostatic repulsive potential. For above reasons, making a homogeneous dispersion of nanoparticles in cement paste matrix is a challenging task. In the worst condition, the socalled nanoparticles filled in cement pastes always contain certain of loosened clusters of particles, leading to properties even worse than blank cement pastes. For NS, it is difficult to further improve its dispersion by tuning DLVO interaction because of calcium ions constantly generated by hydration process. 


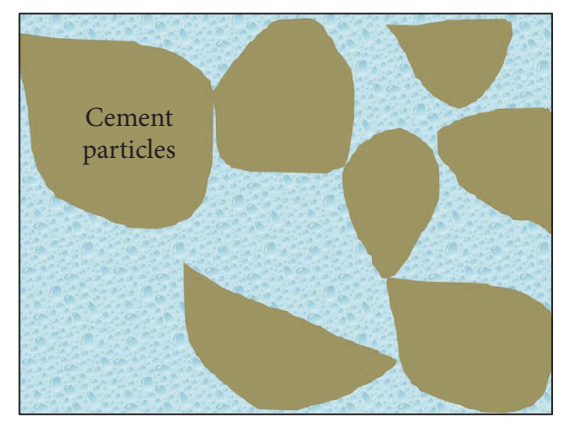

(a)

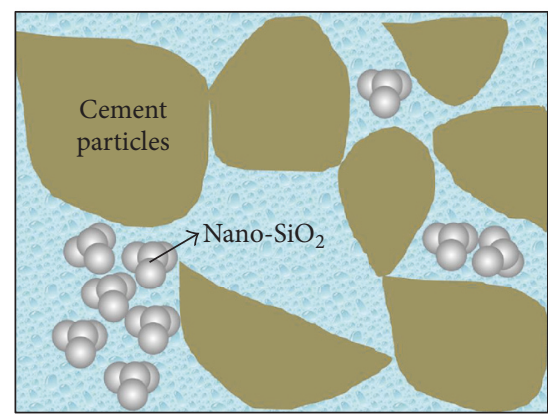

(c)

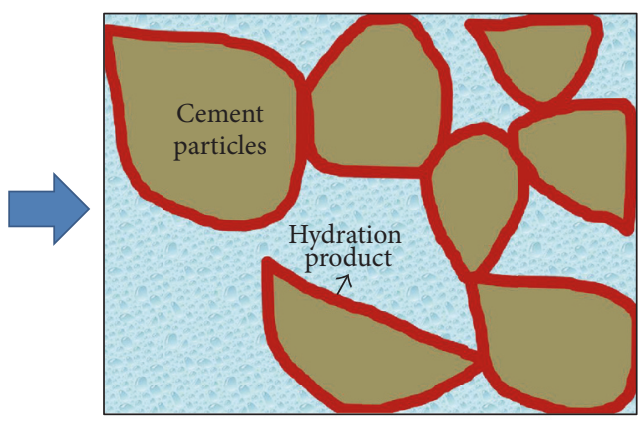

(b)

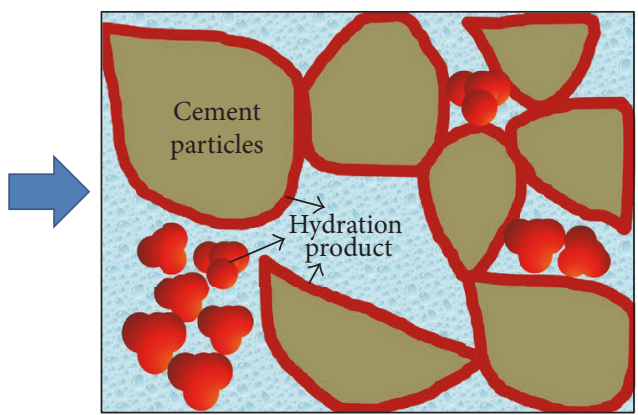

(d)

FIGURE 17: Schematic representation for seeding effect.

The surface modification method brings hope for NS to mitigate the agglomeration phenomenon in the solution with complex ions, because the polymer on particle surface could provide the extra potential barrier. This barrier comes from the steric repulsive force related to the conformation of polymer itself. For NS@PCE, it was designed based on the idea of surface modification. In previous study, as expected, NS@PCE could form a more stable nanosuspension than pristine NS in portlandite saturation, and the stability degree is improved with the shell-core ratio increasing [18]. Although the polymer on the surface could improve the dispersion property, on the other hand, the surface modification of NS also has the side effect that decreases pozzolanic reactivity of nanoparticles, which is due to the fact that the polymer on the surface would shield the attack of alkaline ion. As proposed by Thomas [13], NS itself is not regarded as the nucleating agent; it should first react with calcium hydroxide to generate the C-S-H nucleus. According to this theory, low pozzolanic reactivity accounts for low growth kinetics of $\mathrm{C}$ $\mathrm{S}-\mathrm{H}$ nucleus. That means that the benefit of good dispersion may be covered, if the pozzolanic reactivity of NS@PCE is too small. To be more specific, a high shell-core ratio would bring about a significant drawback for NS@PCE as verified by the hydration heat results of NS@PCE-3-added samples. Based on the discussion above, the schematic drawing for the dispersion and nucleation process of NS and NS@PCE is demonstrated in Figure 18.

In general, the effect of surface modification has two sides. It is important to keep in mind that if accelerating cement hydration is our core need, there is always a balance between initial dispersion and pozzolanic reactivity for NS@PCE.
We should balance trade-offs among those two effects to design an optimal shell-core ratio for NS@CPE. In addition, this interpretation about balance would also inspire us to engineer the NS@PCE with high shell-core ratio to make NS@PCE conforming to the requirement of retarding cement hydration.

\section{Conclusions}

This paper has described the generalized influence of NS@PCE on accelerating the rate of cement hydration. Factors of the dosage and disparity in surface properties (quantified by shell-core ratio) are distinguished and analyzed in the light of their influence on hydration rate. From this study, the following conclusions can be drawn:

(1) Although a series of NS@PCE and NS have a similar particle size distribution, they exhibit different influences on cement hydration. This is not in agreement with the traditional viewpoint that the acceleration effect is proportional to the increase of surface area provided by nanoparticles.

(2) A moderate shell-core ratio (NS@PCE-2) shows more effect in accelerating cement hydration among a series of NS@PCE at the dosage of 1\%.

(3) The optimal dosage of NS@PCE-2 is around 2\%. At the same dosage, the accelerating effect of NS@PCE2 is more pronounced than pristine NS. 


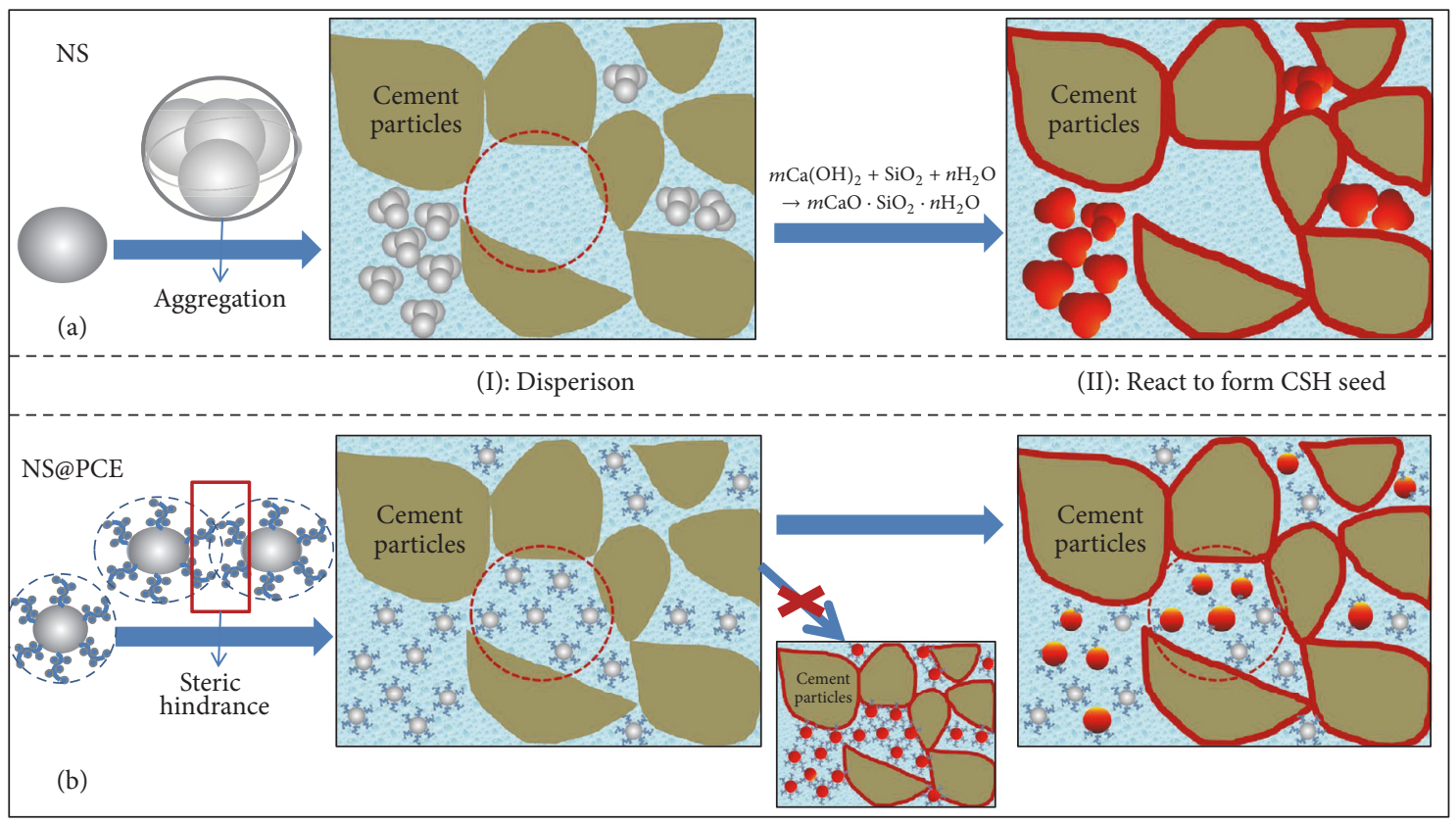

FIGURE 18: Schematic representation for dispersion and nucleation: (a) NS and (b) NS@PCE.

(4) For cement paste with NS@PCE, there is a linear correlation between cumulative heat release and compressive strength. It suggests that the time-dependent evolution of mechanical properties in cementitious materials with NS@PCE could be estimated by heat evolution data.

(5) A hypothesis is proposed to explain the effect of NS@PCE, which highlights a balance between initial dispersion and pozzolanic reactivity for NS@PCE. Based on this hypothesis, either accelerating effect or retarding effect could be achieved by controlling surface properties of NS.

Besides, the outcomes of this study provide new insight into controlling the cement hydration by modifying the surface property of supplementary cementitious materials.

\section{Conflicts of Interest}

The authors declare that there are no financial conflicts of interest.

\section{Acknowledgments}

The authors would like to acknowledge the financial support by the National Natural Science Foundation of China (Grants nos. 51408273 and 51438003), Excellent Doctoral Dissertations Cultivation Fund from Southeast University, and the China Scholarship Council.

\section{References}

[1] F. Xi, S. J. Davis, P. Ciais et al., "Substantial global carbon uptake by cement carbonation," Nature Geoscience, vol. 9, no. 12, pp. 880-883, 2016.
[2] L. K. Turner and F. G. Collins, "Carbon dioxide equivalent (CO2-e) emissions: a comparison between geopolymer and OPC cement concrete," Construction and Building Materials, vol. 43, pp. 125-130, 2013.

[3] M. Liu, Z. Zhou, X. Zhang, X. Yang, and X. Cheng, "The synergistic effect of nano-silica with blast furnace slag in cement based materials," Construction and Building Materials, vol. 126, pp. 624-631, 2016.

[4] T. Yehdego and S. Peethamparan, "The role of nano silica in modifying the early age hydration kinetics of binders containing high volume fly ashes," in Nanotechnology in Construction, pp. 399-405, Springer International Publishing, Cham, Switzerland, 2015.

[5] P. Hou, K. Wang, J. Qian, S. Kawashima, D. Kong, and S. P. Shah, "Effects of colloidal nanoSiO $\mathrm{O}_{2}$ on fly ash hydration," Cement and Concrete Composites, vol. 34, no. 10, pp. 1095-1103, 2012.

[6] Z. Rong, W. Sun, H. Xiao, and G. Jiang, "Effects of nano- $\mathrm{SiO}_{2}$ particles on the mechanical and microstructural properties of ultra-high performance cementitious composites," Cement and Concrete Composites, vol. 56, pp. 25-31, 2015.

[7] A. Nazari and S. Riahi, " $\mathrm{Al}_{2} \mathrm{O}_{3}$ nanoparticles in concrete and different curing media," Energy and Buildings, vol. 43, no. 6, pp. 1480-1488, 2011.

[8] A. Nazari and S. Riahi, "The effect of $\mathrm{TiO}_{2}$ nanoparticles on water permeability and thermal and mechanical properties of high strength self-compacting concrete," Materials Science and Engineering A, vol. 528, no. 2, pp. 756-763, 2010.

[9] R. Zhang, X. Cheng, P. Hou, and Z. Ye, "Influences of nano$\mathrm{TiO}_{2}$ on the properties of cement-based materials: hydration and drying shrinkage," Construction and Building Materials, vol. 81, pp. 35-41, 2015.

[10] M. Heikal and N. S. Ibrahim, "Hydration, microstructure and phase composition of composite cements containing nanoclay," Construction and Building Materials, vol. 112, pp. 19-27, 2016. 
[11] C. Lin, W. Wei, and Y. H. Hu, "Catalytic behavior of graphene oxide for cement hydration process," Journal of Physics and Chemistry of Solids, vol. 89, pp. 128-133, 2016.

[12] J. J. Thomas, J. J. Biernacki, J. W. Bullard et al., "Modeling and simulation of cement hydration kinetics and microstructure development," Cement and Concrete Research, vol. 41, no. 12, pp. 1257-1278, 2011.

[13] J. J. Thomas, H. M. Jennings, and J. J. Chen, "Influence of nucleation seeding on the hydration mechanisms of tricalcium silicate and cement," Journal of Physical Chemistry C, vol. 113, no. 11, pp. 4327-4334, 2009.

[14] K. L. Scrivener, P. Juilland, and P. J. M. Monteiro, "Advances in understanding hydration of Portland cement," Cement and Concrete Research, vol. 78, pp. 38-56, 2015.

[15] T. Oertel, U. Helbig, F. Hutter, H. Kletti, and G. Sextl, "Influence of amorphous silica on the hydration in ultra-high performance concrete," Cement and Concrete Research, vol. 58, pp. 121-130, 2014.

[16] A. Bagheri, T. Parhizkar, H. Madani, and A. M. Raisghasemi, "The influence of different preparation methods on the aggregation status of pyrogenic nanosilicas used in concrete," Materials and Structures, vol. 46, no. 1-2, pp. 135-143, 2013.

[17] M. Iijima and H. Kamiya, "Surface modification for improving the stability of nanoparticles in liquid media," KONA Powder and Particle Journal, vol. 27, pp. 119-129, 2009.

[18] Y. Gu, Q. Ran, X. Shu, C. Yu, H. Chang, and J. Liu, "Synthesis of nanoSiO $\mathrm{O}_{2} @ \mathrm{PCE}$ core-shell nanoparticles and its effect on cement hydration at early age," Construction and Building Materials, vol. 114, pp. 673-680, 2016.

[19] J. W. Bullard, H. M. Jennings, R. A. Livingston et al., "Mechanisms of cement hydration," Cement and Concrete Research, vol. 41, no. 12, pp. 1208-1223, 2011.

[20] H. Taylor, Cement Chemistry, Thomas Telford Publishing, London, UK, 1997.

[21] G. Land and D. Stephan, "Controlling cement hydration with nanoparticles," Cement and Concrete Composites, vol. 57, pp. 6467, 2015.

[22] A. Ayuela, J. S. Dolado, I. Campillo et al., "Silicate chain formation in the nanostructure of cement-based materials," The Journal of Chemical Physics, vol. 127, no. 16, Article ID 164710, 2007.

[23] J. S. Dolado, I. Campillo, E. Erkizia et al., "Effect of nanosilica additions on belite cement pastes held in sulfate solutions," Journal of the American Ceramic Society, vol. 90, no. 12, pp. 3973-3976, 2007.

[24] A. Nazari and S. Riahi, "The effects of $\mathrm{SiO}_{2}$ nanoparticles on physical and mechanical properties of high strength compacting concrete," Composites Part B: Engineering, vol. 42, no. 3, pp. 570-578, 2011.

[25] L. P. Singh, D. Ali, and U. Sharma, "Studies on optimization of silica nanoparticles dosage in cementitious system," Cement and Concrete Composites, vol. 70, pp. 60-68, 2016.

[26] P. Hou, S. Kawashima, D. Kong, D. J. Corr, J. Qian, and S. P. Shah, "Modification effects of colloidal nanoSiO ${ }_{2}$ on cement hydration and its gel property," Composites Part B: Engineering, vol. 45, no. 1, pp. 440-448, 2013.

[27] D. P. Bentz, T. Sato, I. De La Varga, and W. J. Weiss, "Fine limestone additions to regulate setting in high volume fly ash mixtures," Cement and Concrete Composites, vol. 34, no. 1, pp. 11-17, 2012.
[28] A. Kumar, T. Oey, S. Kim et al., "Simple methods to estimate the influence of limestone fillers on reaction and property evolution in cementitious materials," Cement and Concrete Composites, vol. 42, pp. 20-29, 2013.

[29] D. P. Bentz, A. S. Hansen, and J. M. Guynn, "Optimization of cement and fly ash particle sizes to produce sustainable concretes," Cement and Concrete Composites, vol. 33, no. 8, pp. 824-831, 2011.

[30] T. Oey, A. Kumar, J. W. Bullard, N. Neithalath, and G. Sant, "The filler effect: the influence of filler content and surface area on cementitious reaction rates," Journal of the American Ceramic Society, vol. 96, no. 6, pp. 1978-1990, 2013.

[31] M. Costoya, Kinetics and Microstructural Investigation on the Hydration of Tricalcium Silicate, École Polytechnique Fédérale de Lausanne, Lausanne, Switzerland, 2008.

[32] Y. Gu, Z. Wei, Q. Ran, X. Shu, K. Lv, and J. Liu, "Characterizing cement paste containing SRA modified nanoSiO ${ }_{2}$ and evaluating its strength development and shrinkage behavior," Cement and Concrete Composites, vol. 75, pp. 30-37, 2017. 

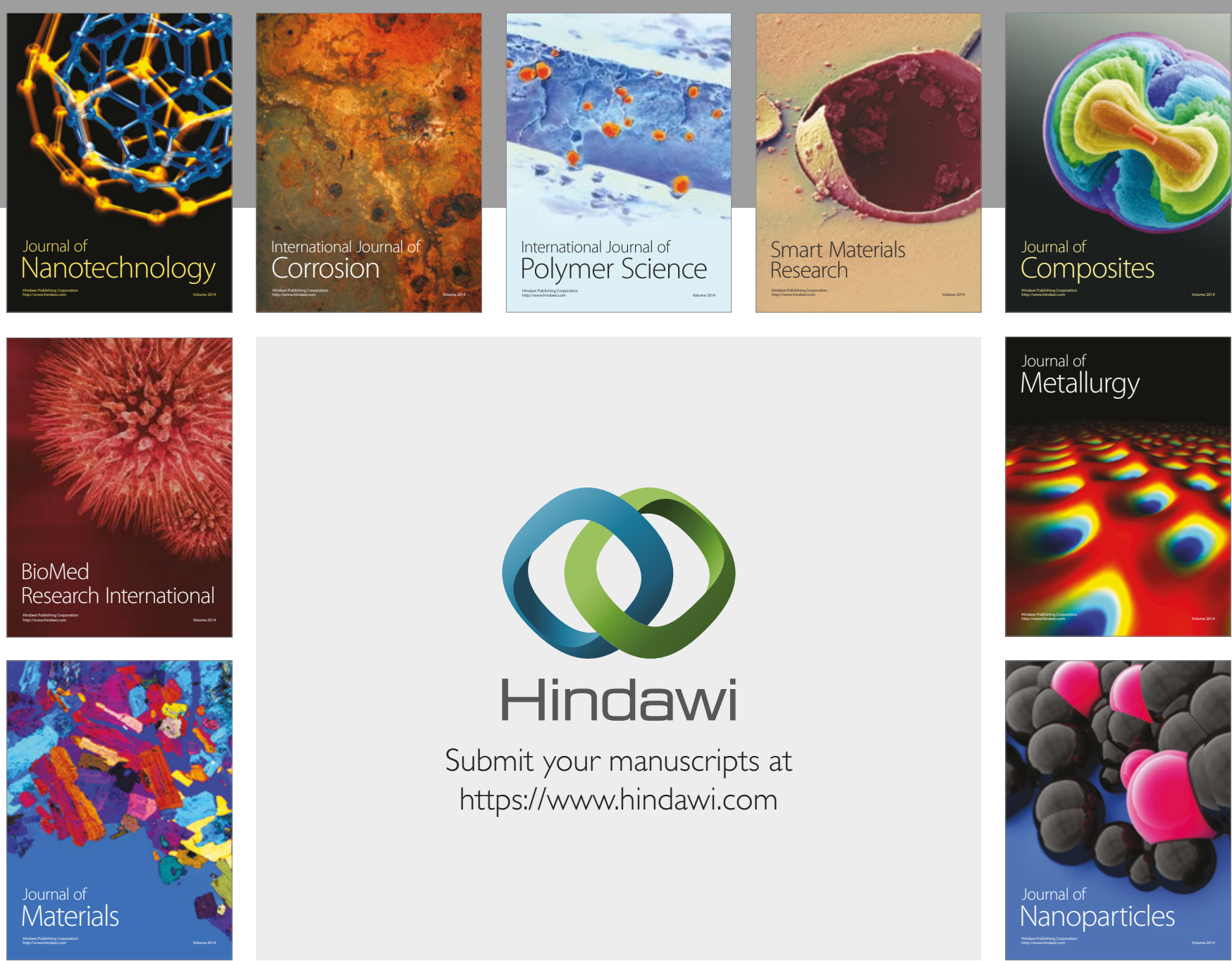

\section{Hindawi}

Submit your manuscripts at

https://www.hindawi.com
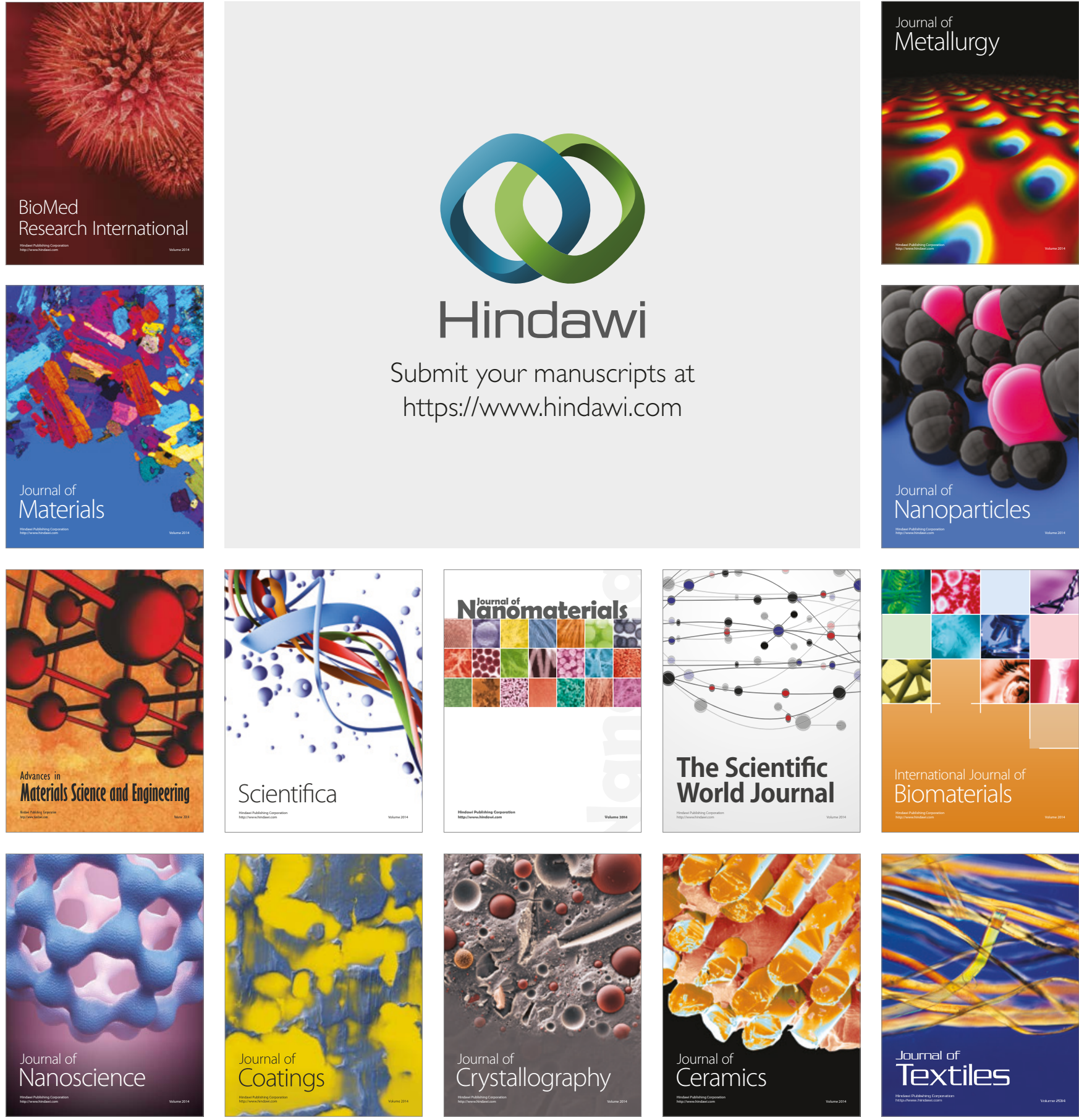

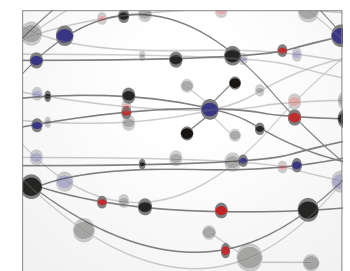

The Scientific World Journal
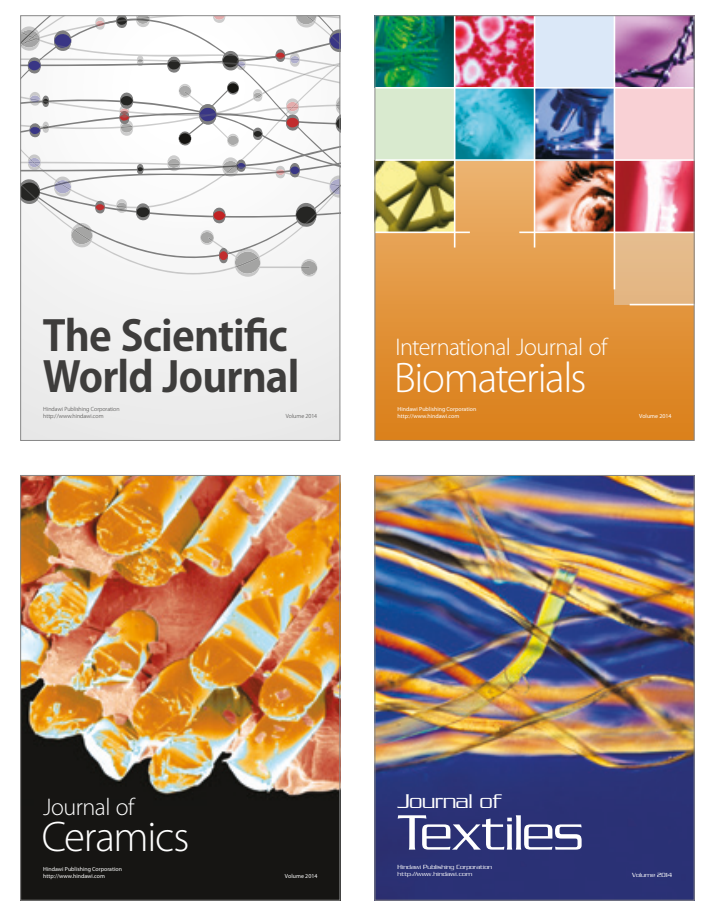